\title{
MULTI-AGENT SYSTEMS BASED INTELLIGENT CONTROL OF MICROGRID
}

\author{
Princy Khamesra ${ }^{1}$, Jitendra Kasera ${ }^{2}$, Rahul Mehta ${ }^{3}$ \\ ${ }^{1}$ P.G. student, Pacific University, Udaipur \\ ${ }^{2}$ Assistant Prof. \& H.O.D. (Electrical Engg.), Pacific University, Udaipur \\ ${ }^{3}$ Phd student, National University of Singapore, Singapore
}

\begin{abstract}
The electric power system supports the operation of developments \& economic growth of the country. The transition of power system towards deregulation \& profit driven operation will led to a decrease of reverse \& reliability of entire power network. It is necessary to design reliable \& autonomous reconfigurable electric power system to secure against natural as well as man-made disasters. The adequate and secure power system concept can be achieved by intelligent or smart micro grid. The smart grid system incorporated with several interconnected sub systems those having cellular structure and capable to operate autonomously during system faults. Every sub system called cell have enough power generating capacity to meet critical load demand with ability of internal communication among generation, transmission, distribution and controlling devices. The smart grid will supply uninterrupted power supply to higher priority loads to maintain integrity of critical infrastructure. This paper presents concepts, components, architect and procedure to implement smart grid system.
\end{abstract}

Keywords: Autonomous, APS, DER, DSM, IDAPS, Smart grid.

\section{INTRODUCTION}

Electricity supply play important role to provide services such as natural gas supply, water supply, transportation, communication, financial, commercial \& health care services. On site distributed energy resources (DER) are installed by commercial and many residential customers to increase reliability of electrical power supply. But still no mechanism to adopt \& coordinate these customer owned DER to supply power to critical load at distribution level. Therefore a place to organize, manage and convert customer owned DER into smart micro grid system to integrate critical load power supply at distribution level. Electrical power generation capacity of distribution system can be organize $\&$ utilized by smart micro grid concepts.

\section{IDAPS MICROGRID}

IDAPS is group of several autonomous power systems. Autonomous power systems are identifying with existing power network for autonomous operation, independent of grid on the event of grid failure. IDAPS secured critical distribution load located near APS during outage/faults via distributed power generations. Intelligent agent provides communication to generator, load \& controlling devices with other elements in the cell. The intelligent agent coordinates with generators, loads \& control utilities to prevent loss of such critical load in smart \& efficient manner.

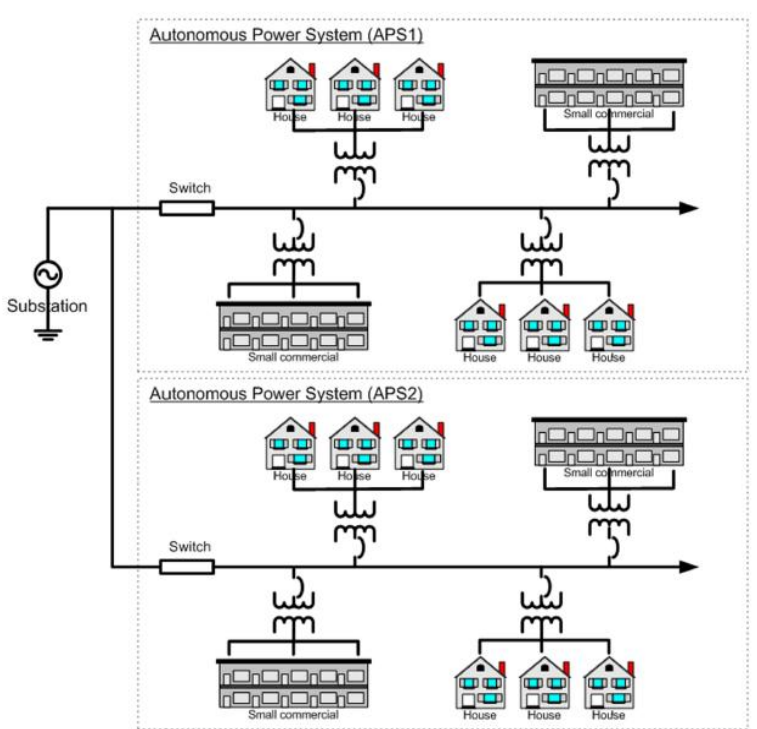

Fig. 1: Typical structure of intelligent distributed autonomous power system.

\subsection{Control \& Communication Architecture}

A framework is developed for intelligent distributed autonomous power system (IDAPS). IDAPS is a special purpose micro grid designed for customer owned DER for residential as well as commercial consumer. Frame work of IDAPS consist physical \& cyber layers. It composed of loosely connected DER and load with communication in one by one manner. IDAPS have two working mode (i) normal operating mode (ii) emergency operating condition. IDAPS structure is complementary of main electric grid in normal operating condition. The end user customers get a choice to buy electricity from nearest available DER if it provides 
either competitive price or green power sources. When a fault detected in grid power supply the DER isolate it self from grid \& start operate autonomously. IDAPS one agent starts communication with another agent and reconfigure \& coordinate IDAPS component in such way to secure critical load on outage/faults.

Some assumptions are made for IDAPS those are:

- Each IDAPS micro grid has sufficient DER capability to secure load situated in each cell on event of outages.

- Technical, regulatory and economic barriers are bypassed for interconnection of distributed generators.

- All DER \& control devices are communicate, interface $\&$ addressed only by IP address.

- One communication medium must be available to communicate generators, load \& controlling devices.

\subsection{IDAPS Supply-Driven-Demand Management}

The IDAPS micro grid has a bulletin board to transact business by electricity buyers and sellers. The decision is based on real time electricity price offered by supplier in grid. The residential as well as commercial customer having choice to buy electricity from most economic distributed generators on normal \& outage conditions. Scheduled availability of electricity supply will be posted on bulletin board with price $\&$ quantity of electricity to be sold for next 24 hours.

\subsection{IDAPS Agent Base Framework}

IDAPS is multi-agent concept which is based on web service layer. Multi-agent system is an idea to break a complex problem into smaller simple problems handled by several entities. A software based entity that sense and respond to change in signal to accomplish individual goal is known as agent. Four types of agents are present in multiagent system.

- Control agent: A control agent has software that can perform synchronization of generators, maintain required operating frequency \& voltage level, sustain reactive \& real power, loading, unloading and other controlling actions.

- DER agent: A DER agent is responsible for controlling \& operation of any DER that is dispatched. DER agent contains ID, location, type, price, quantity and availability of associated DER.

- User agent: User agent provides a gateway to enter a user into the rest of the system. It collects real time information \& display all related information on electronic console on the end user premises. User agent provides price, quantity, availability for buying from bulletin board with electricity price information from utilities.

- Database agent: A database agent keep database electricity price \& demand information. Users \& other agents can access this database via database agent.

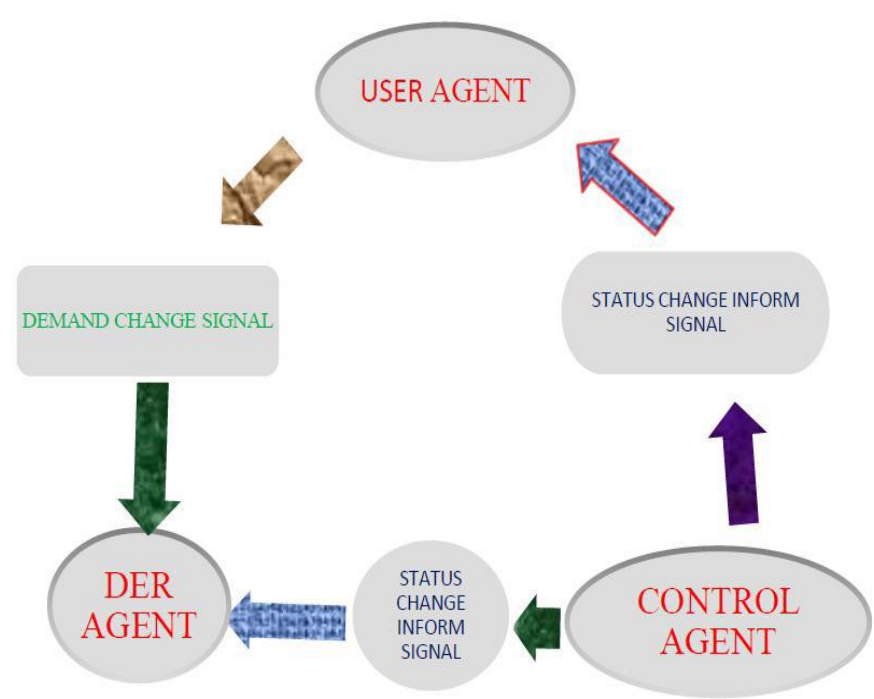

Fig. 2: Messages exchanged among agents and physical entities.

\section{FLOWCHART FOR USER AGENT OPERATION}

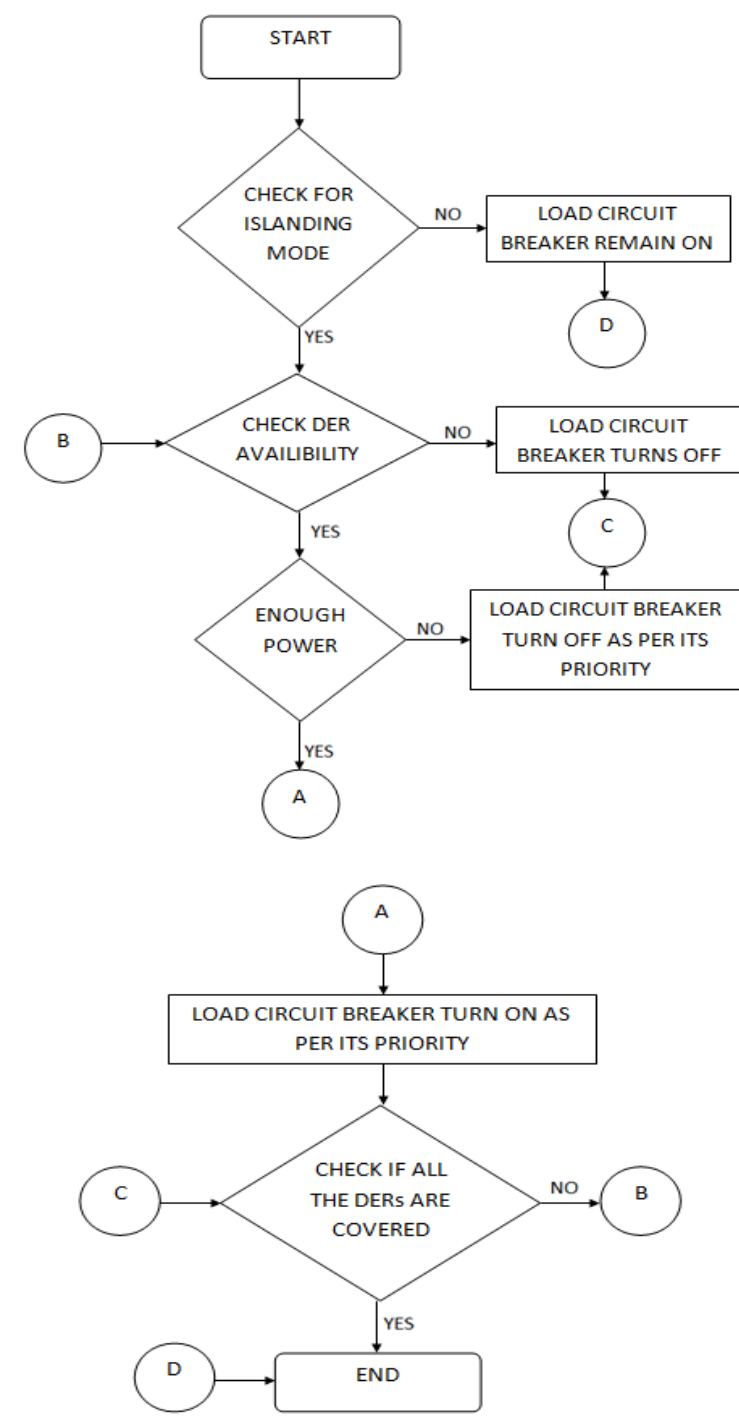

Fig. 3: Flowchart for User agent operation. 


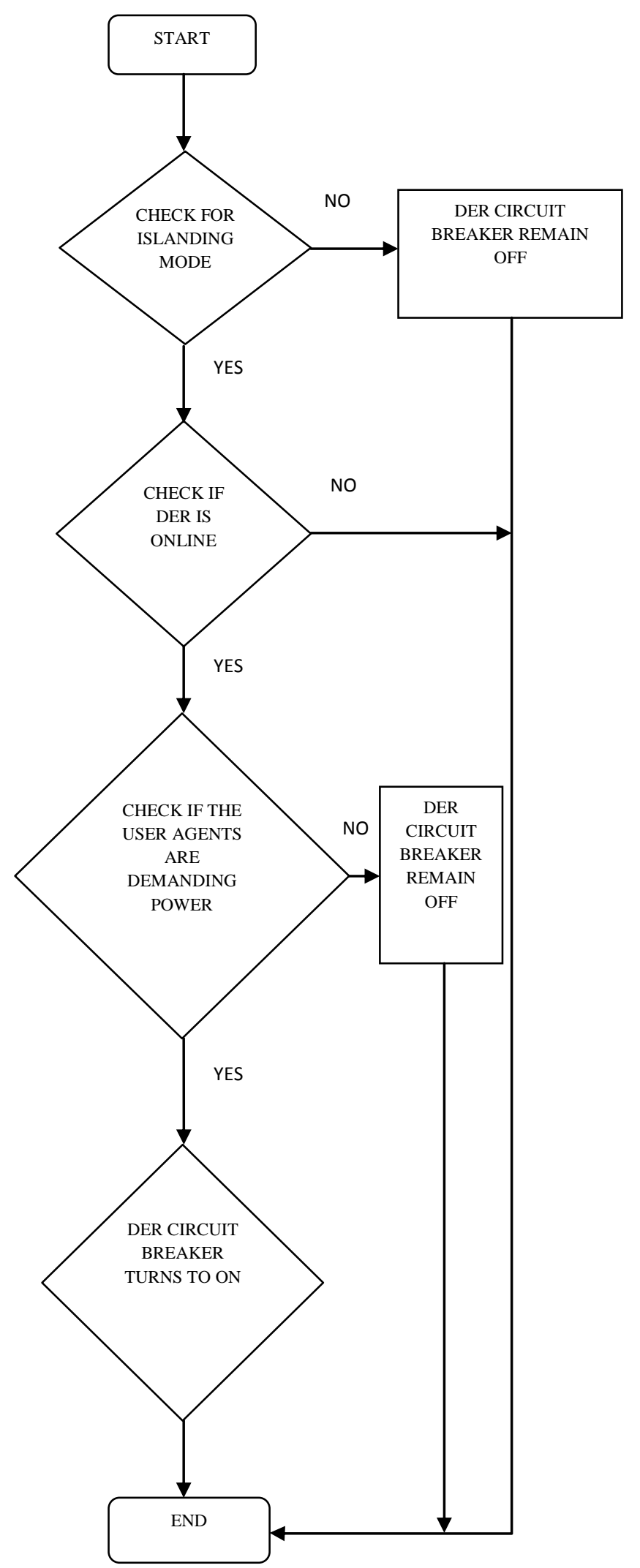

Fig. 4: Flowchart for DER agent operation.

\section{SIMULATIONS \& RESULTS}

A MATLAB model of IDAPS is developed. The proposed model has three 65KVA distributed generators, two critical loads $50 \mathrm{KW}$ each, normal load $50 \mathrm{KW} \&$ circuit breakers.

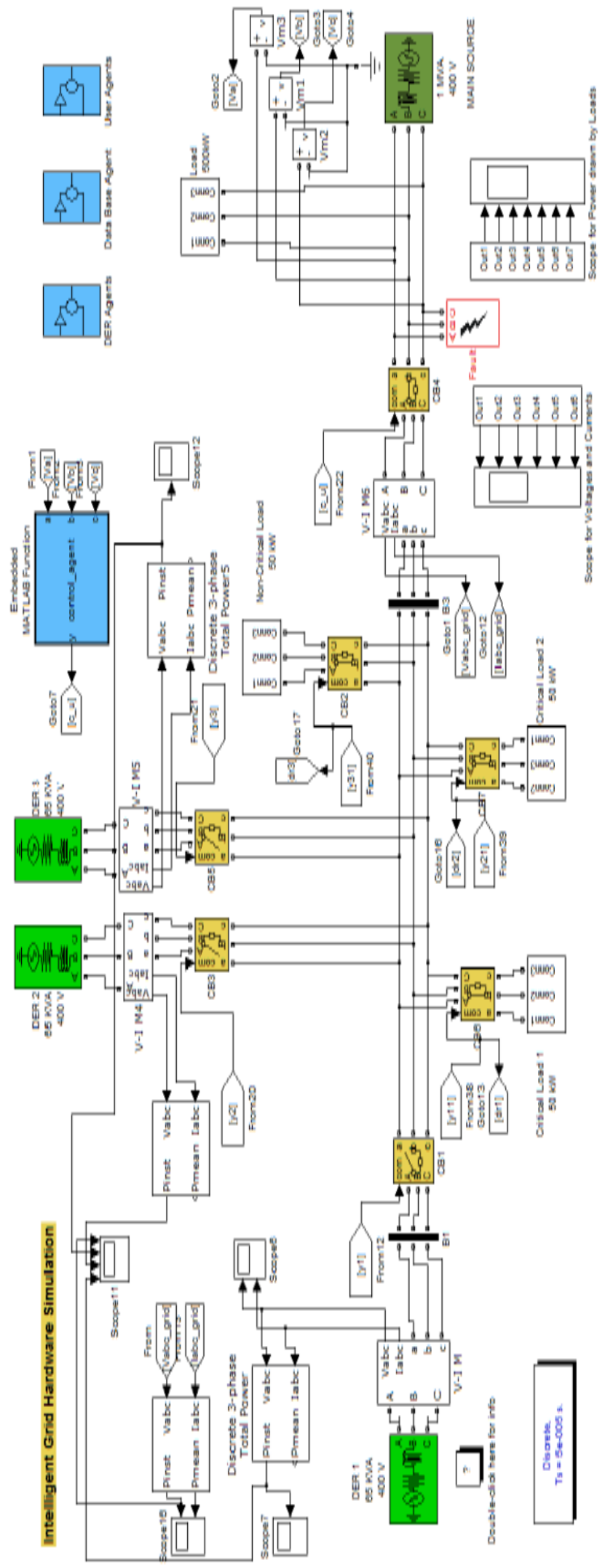

Fig. 5: IDAPS smart Grid Hardware Simulation. 


\section{RESULTS}

Three cases are observed with proposed model.

\subsection{Transition from Grid-Connected to Islanded} Mode and Securing Critical Loads

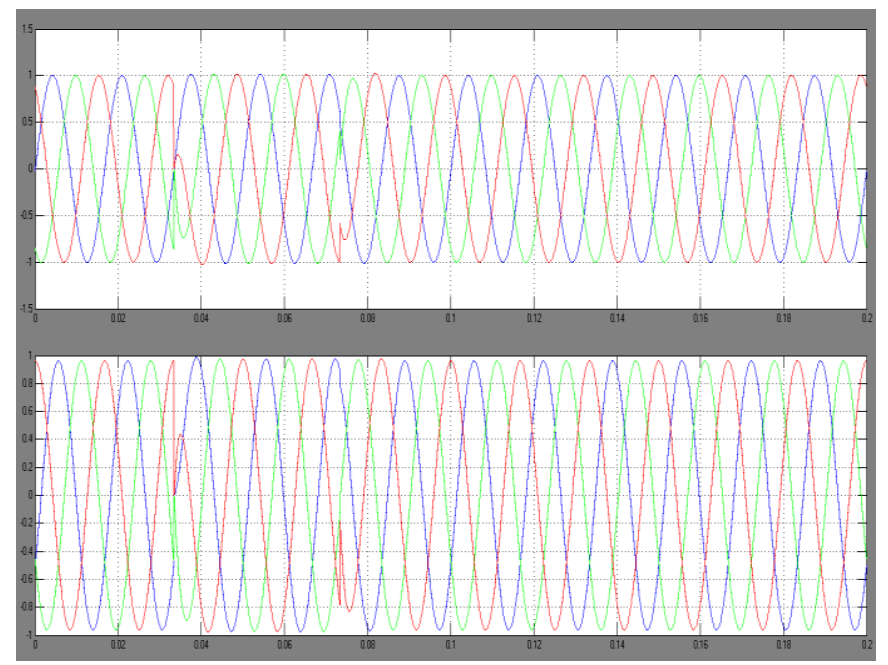

Fig. 6(a): Voltage and current waveform for critical load 1.

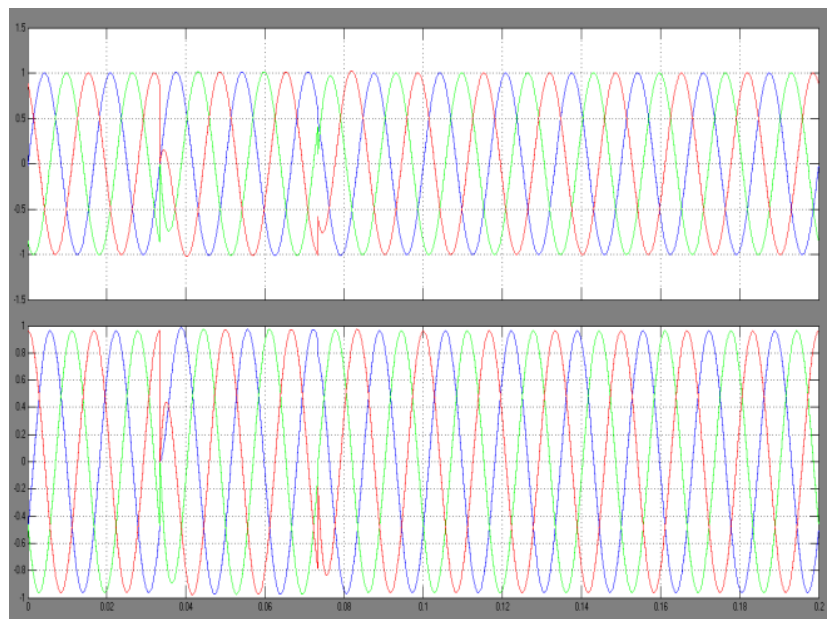

Fig. 6(b): Voltage and current waveform for critical load 2.

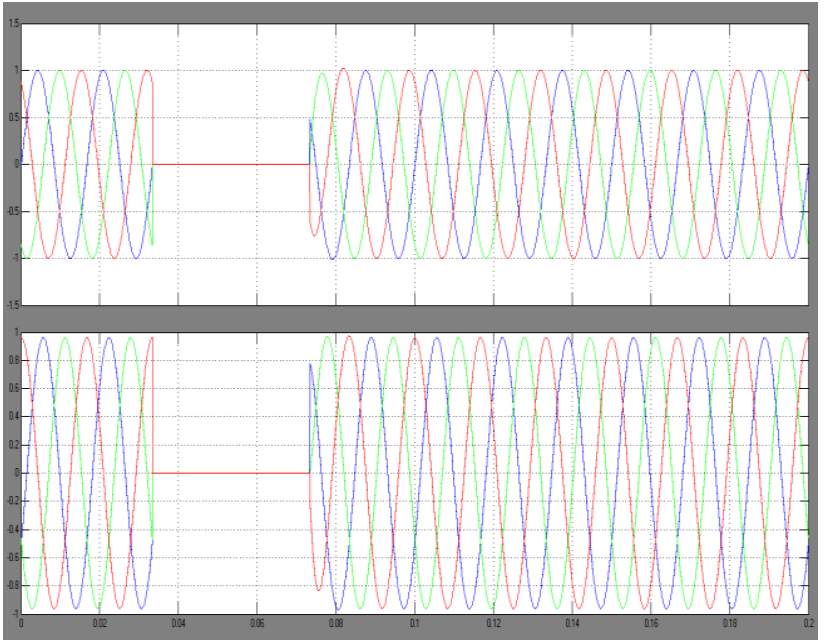

Fig. 6(c): Voltage and current waveform for non-critical load.

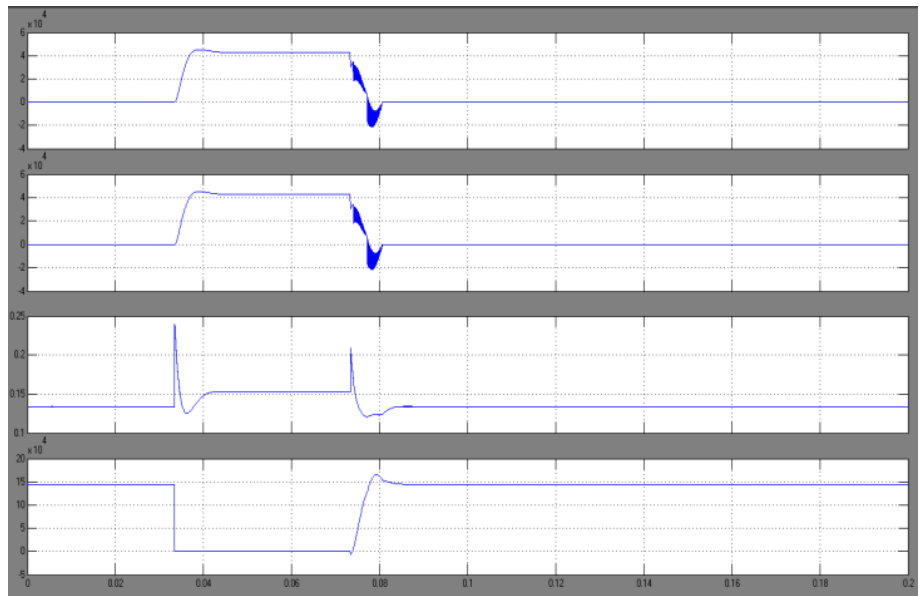

Fig. 6(d): Power taken from DER1, DER2, DER3 and the main grid.

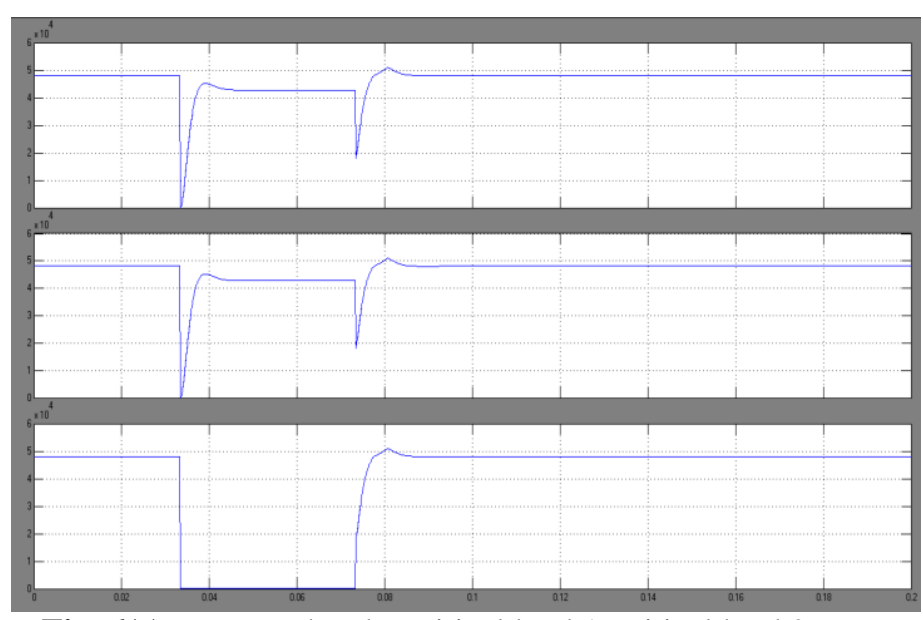

Fig. 6(e): Power taken by critical load 1, critical load 2, non-critical load

\subsection{Transition from Grid-Connected to Islanded} Mode and Securing Critical Loads as well as NonCritical loads 


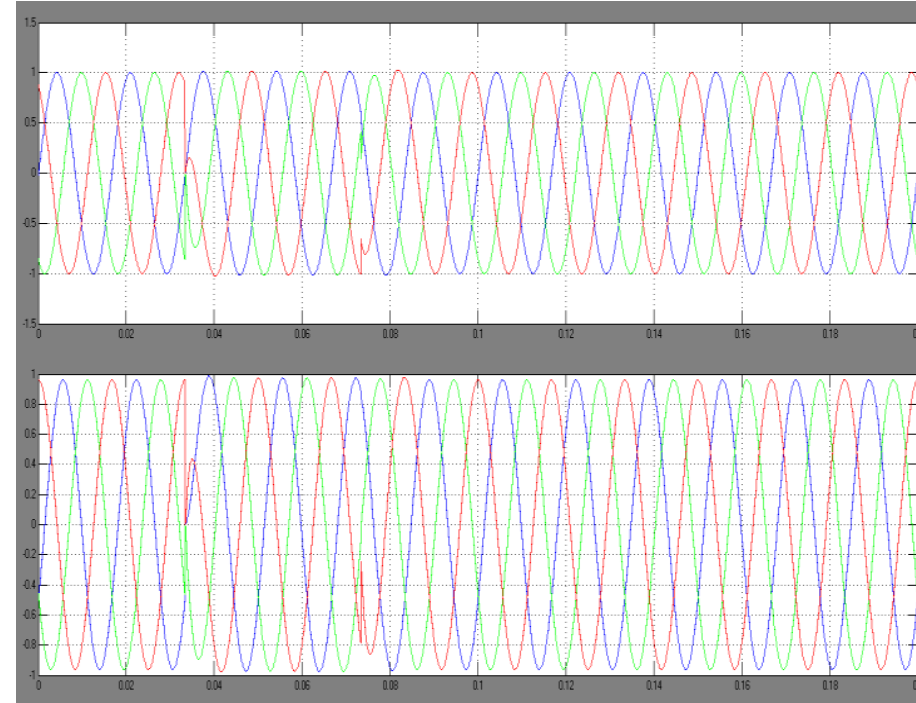

Fig. 7(a): Voltage and current waveform for critical load 1

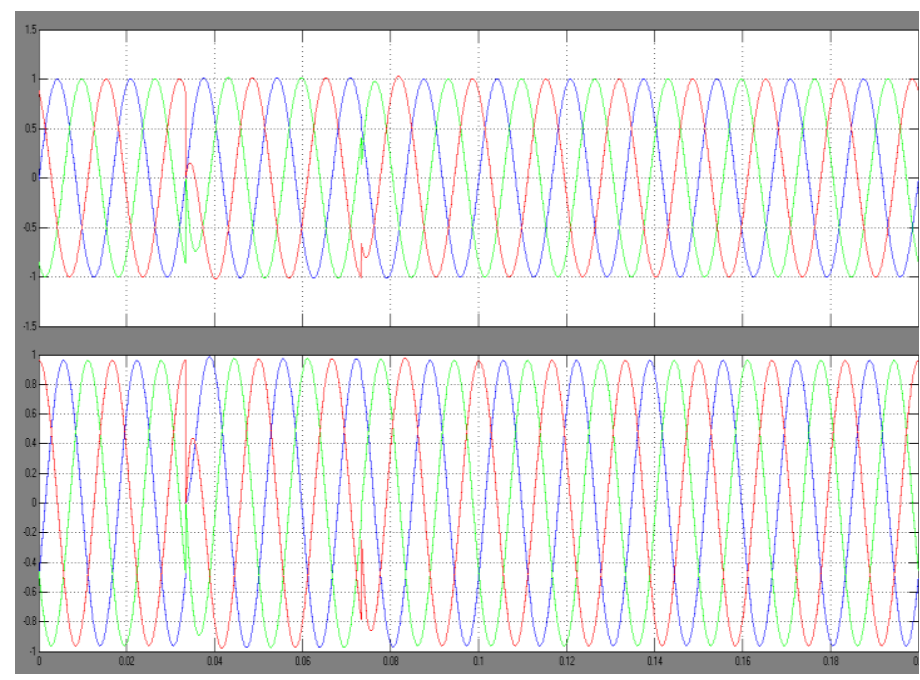

Fig. 7(b): Voltage and current waveform for critical load 2

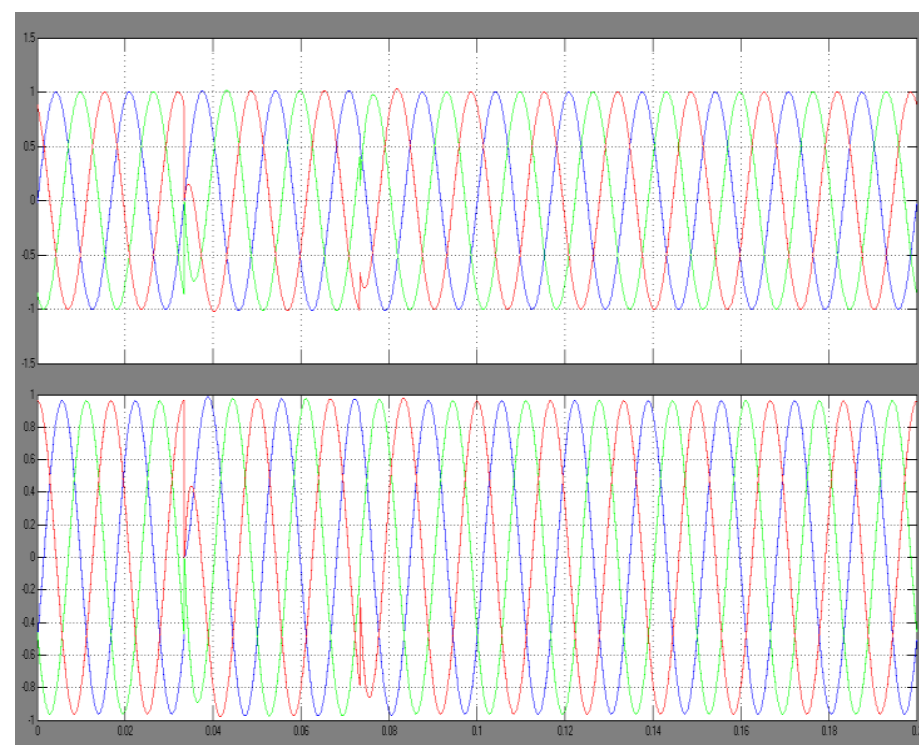

Fig. 7(c): Voltage and current waveform for non-critical load

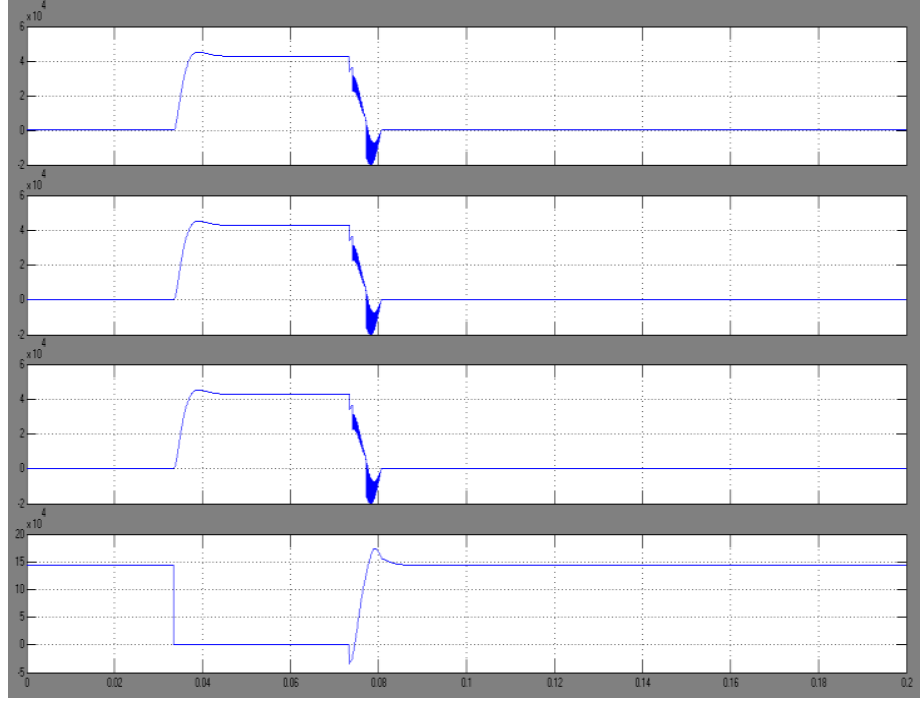

Fig. 7(d): Power taken from DER1, DER2, DER3 and the main grid

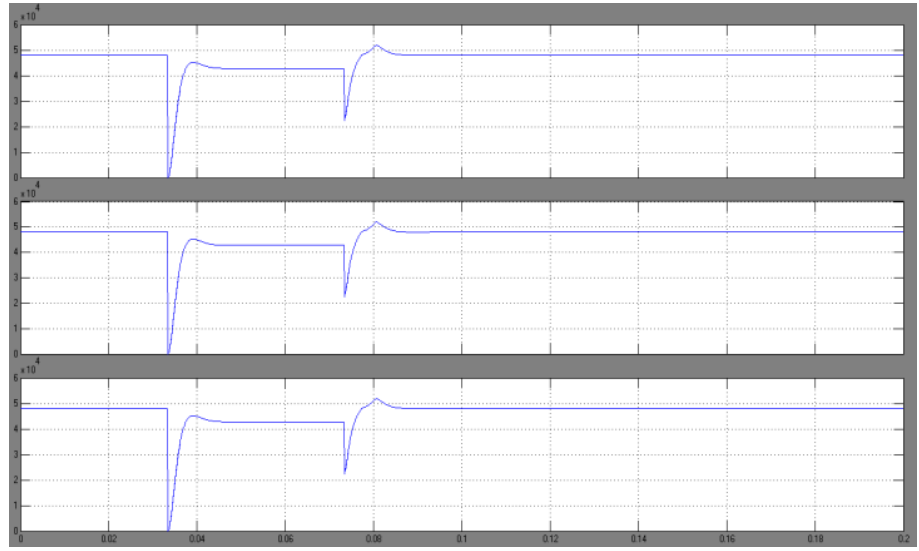

Fig. 7(e): Power taken by critical load 1, critical load 2, non-critical load

\subsection{Transition from Grid-Connected to Islanded} Mode considering Load Variations.

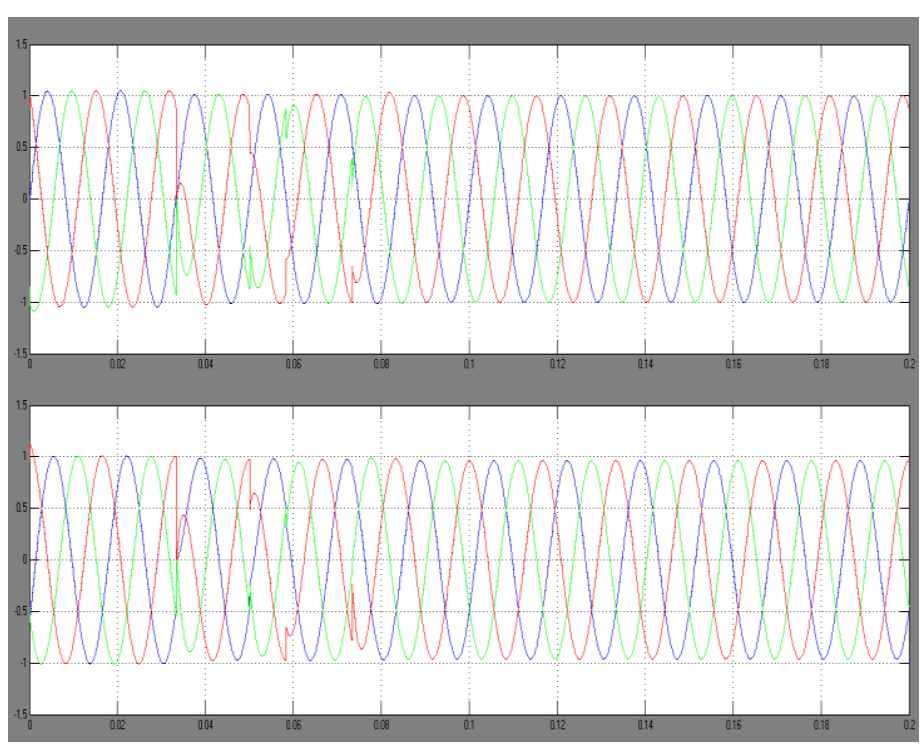

Fig 8(a): Voltage and current waveform for critical load 1 

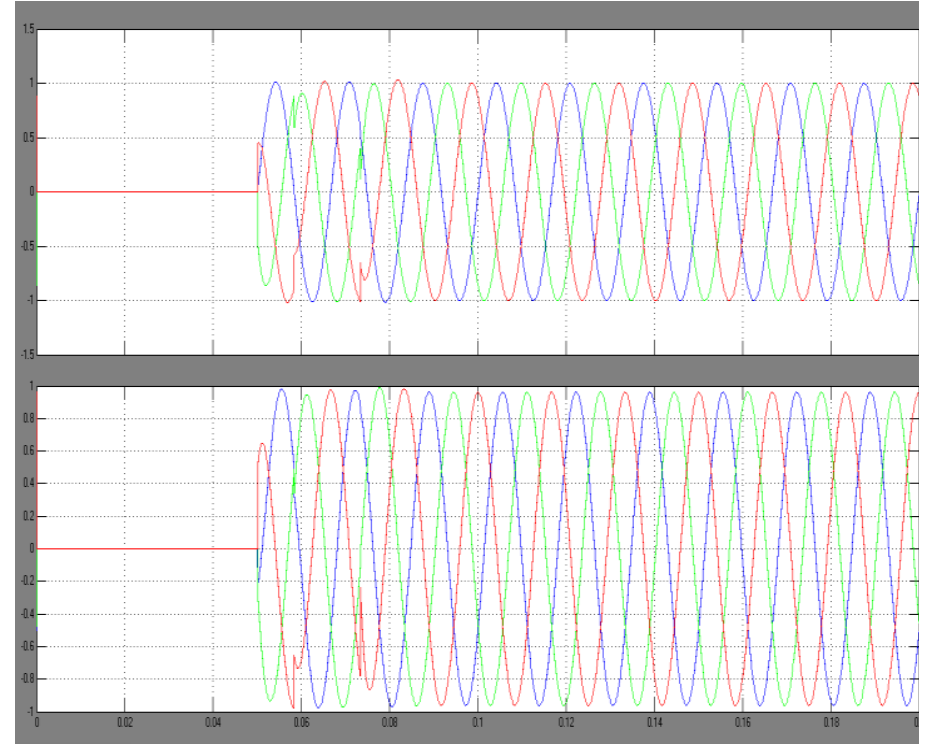

Fig 8(b): Voltage and current waveform for critical load 2

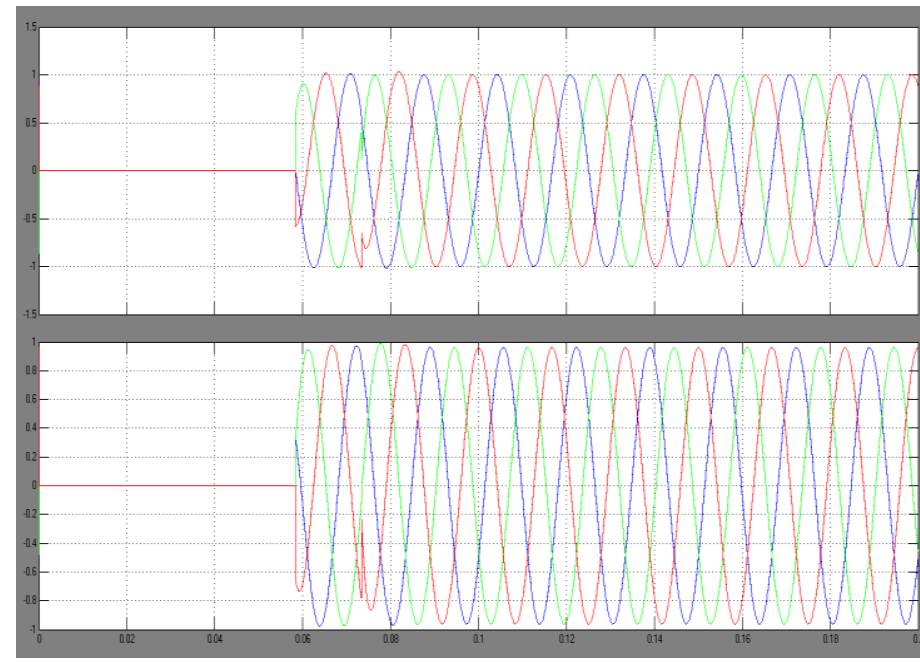

Fig 8(c): Voltage and current waveform for non- critical load

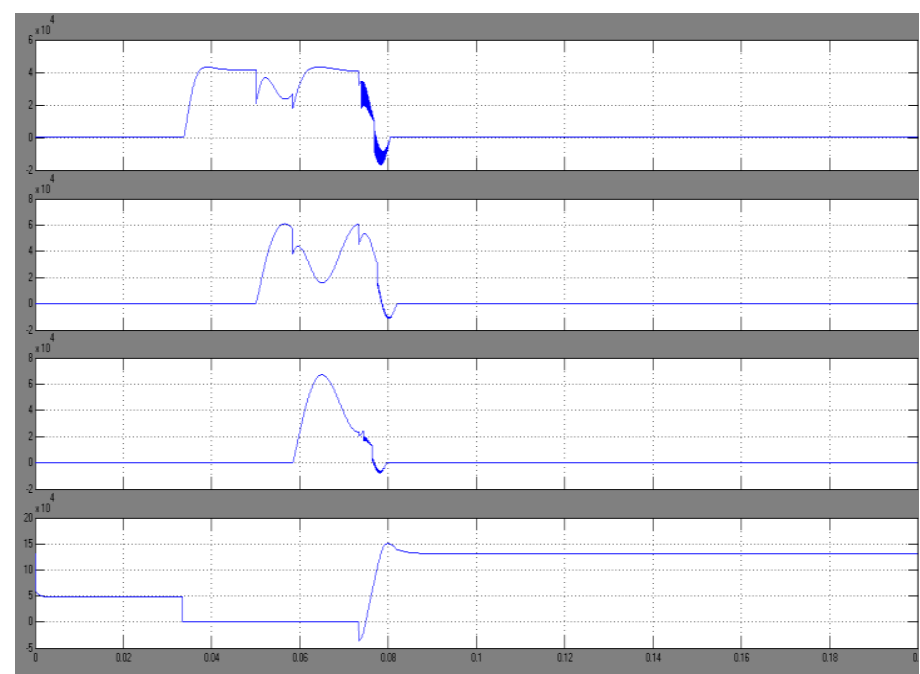

Fig 8(d): Power taken from DER1, DER2, DER3 and the main grid

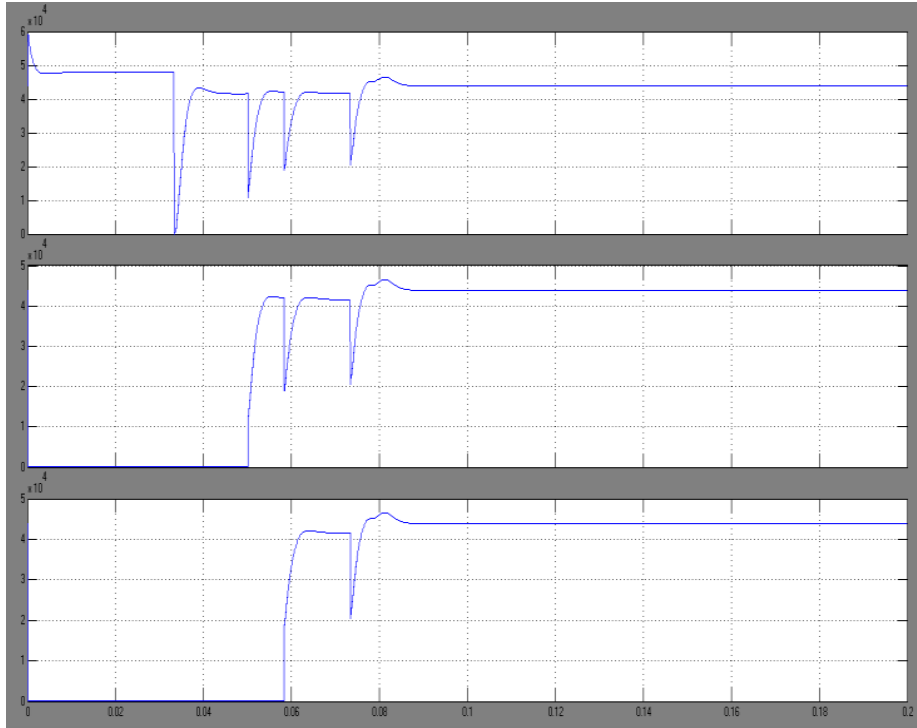

Fig 8(e): Power taken by critical load 1, critical load 2, noncritical load

\section{CONCLUSIONS}

The Intelligent Distributed Autonomous Power System (IDAPS) concept is presented, also describing the IDAPS parts \& simulation model. The main focuses on coordinating DER units concern with the same utility. The IDAPS designed for managing customer owned DER in the distribution network. The novel supply-driven-demand management model keep demand side management (DSM) within the IDAPS micro grid under normal operating conditions and allows critical loads to be served during emergency conditions. IDAPS micro grid communicates with one another and also ensures portability and interoperability among various DG systems via utilization of web services enables components.

\section{REFERENCES}

[1] Pipattanasomporn, M., Feroze, H., Rahman, S., "Multi-Agent Systems in a Distributed Smart Grid: Design and Implementation", IEEE Power Systems Conference and Exposition, Seattle, WA, USA, March 15-18, 2009.

[2] S. Rahman, M. Pipattanasomporn and Y. Teklu, "Intelligent Distributed Autonomous Power Systems (IDAPS)", in Proc. of the IEEE PES Annual General Meeting, Tampa,Florida, pp. 8, 2007.

[3] A. Dimeas and N.D Hatziargyriou, "Operation of a multiagent system for microgrid control", IEEE transaction on Power Systems, Vol. 20, No. 3, pp. 1447-1455, 2005

[4] S.D.J. McArthur, E.M. Davidson, J.A. Hossack, and R. McDonald, "Automating power system fault diagnosis through multi-agent system technology", in Proc. of the 37th Hawaii International Conference on System Sciences, 8pp, 2004.

[5] A. Dimeas and N.D Hatziargyriou, "Operation of a multiagent system for microgrid control", in Power Engineering Society General Meeting, Vol. 1, pp. 55$58,2004$. 
[6] J. Hossack, S.D.J. Mcanhur, J.R. Mcdonald, J. Stokoe and T. Cumming, "A multi-agent approach to power system disturbance diagnosis", in Proc. of International conference on power system management and control, Vol. 488, pp. 317-322, 2002.

[7] T. Nagata and H. Sasaki, "A multi-agent approach to power system restoration", IEEE Transactions on Power Systems, Vol. 17, pp. 457-462, 2002.

[8] H.F. Wang, "Multi-agent co-ordination for the secondary voltage control in power system contingencies", in Proc. of IEE Generation, Transmission and Distribution, Vol. 148, pp. 61-66, 2001. 